\title{
Baroreflex Sensitivity in Chronic Obstructive Pulmonary Disease and its Correlation with Disease Severity-in South Indian Population
}

\author{
Ganesan R. ${ }^{1}$, Gaur G.S. ${ }^{2}$, Karthik S. ${ }^{3}$, Vishnukanth G. ${ }^{4}$ \\ ${ }^{1}$ Assistant Professor, Department of Physiology MAPIMS, ${ }^{2}$ Professor, Department of Physiology, \\ JIPMER, ${ }^{3}$ Associate Professor, Department of Physiology, JIPMER ${ }^{4}$, Associate Professor, \\ Department of Pulmonary Medicine, JIPMER
}

\begin{abstract}
Background: Chronic obstructive pulmonary disease (COPD) is systemic disorder which causes autonomic dysfunction and predisposes patients to cardiovascular mortality and morbidity. FEV1 is a predictor of cardiovascular events in COPD patients and Baroreflex sensitivity (BRS) is most reliable tool to measure autonomic dysfunction. There is paucity of literature, revealing the relationship of BRS with disease severity in COPD patients.
\end{abstract}

Objective: In our study we intended to assess BRS among different stages of COPD (GOLD CRITERIA) and also identify the association of BRS with disease severity.

Method: This study was done in collaboration between Department of Physiology \& Department of Pulmonary medicine, JIPMER. It is a descriptive study done on $(n=130)$ male COPD patients. Anthropometric parameters (height, weight, BMI, W/H ratio), basal parameters, BRS (using Finapres) \& PFT (using Spirolab III) parameters were assessed in them. Later, based on the GOLD stage criteria (Mild, Moderate, Severe, Very severe) they were divided into 4 sub-groups. Data was analyzed by SPSS 16.0 version software. One-way ANOVA (>2 groups) was used to find any Statistical difference between the groups. Correlations between the variables were done using Pearson correlation test.

Results: Statistically significant $(\mathrm{p}<0.05)$ difference in BRS between different stages of COPD was determined by Kruskal- Wallis test and the post - hoc (Dunn's) test revealed that BRS levels were significantly reduced in very severe, severe and moderate COPD patients when compared to mild COPD patients. Significant positive Correlation $(\mathrm{r}=.332, \mathrm{p}=0.05)$ was found between BRS and FEV1.

Conclusion: Baroreflex sensitivity is reduced in male patients of COPD and BRS correlated with lung function and disease severity.

Keywords: Autonomic dysfunction, BRS, COPD, Cardiovascular risk, FEV1, GOLD criteria.

\section{Introduction}

Chronic obstructive pulmonary disease (COPD) is

\section{Corresponding Author:}

\section{Dr. Ganesan R.}

Assistant Professor, MAPIMS, Address: No. $97^{\text {th }}$ Cross

St, Ambal Nagar Puducheery-9

e-mail: ganeshraj2511@gmail.com

Mobile No.: 9626911125 a lung disease characterized by chronic obstruction of lung airways which is not entirely reversible. ${ }^{1}$ According to $\mathrm{WHO}$, the burden of COPD is 65 million around the world. ${ }^{2}$ COPD was predicted to be the third most common cause of death by $2020 .^{2}$ In India, burden of COPD -14.84 million, out of which 2 to $22 \%$ are men and 1.2 to $19 \%$ are women. 3,4

COPD causes deaths in $90 \%$ of patients in low-andmiddle-income countries. ${ }^{2,5}$ In India, the mortality rate 
of COPD is $64.7 \%$ which is highest in the world ${ }^{6} \mathrm{COPD}$ is now recognized as the systemic inflammatory disease, which is known to cause extra pulmonary manifestations and predispose patients to increased mortality and morbidity. ${ }^{7}$ The common systemic co-morbid conditions associated with COPD are cardiovascular diseases $(\mathrm{CVD})^{8}$ which accounts for $50 \%$ of COPD deaths. ${ }^{2,9,10}$ For decades, cigarette smoking was thought to be the significant risk factor for cardiovascular disease in COPD . Now studies have proved that COPD is an independent risk factor for development of cardiovascular disease ${ }^{12-14}$ and showed that lower the FEV1, the higher the risk of CVD in COPD patients. ${ }^{15}$ This is because the levels of FEV1 were known to be reduced in low grade systemic inflammatory conditions such as in COPD. ${ }^{16}$ Since low-grade systemic inflammation is associated with atherosclerosis, reduced FEV1 might be a significant risk factor for cardiovascular morbidity and mortality, independent of cigarette smoking, hypertension and serum cholesterol. ${ }^{17,18}$ Lung Health Study showed that age, male gender, married state, smoking, higher diastolic blood pressure and reduced pulmonary function were the most potent cardiovascular risk factors in COPD, while smoking cessation, education, high forced expiratory volume in one second (FEV1) and alcohol use were protective. ${ }^{11}$

COPD also increases sympathetic drive and causes autonomic dysfunction. ${ }^{19,20}$ This is again a possible risk factor for CVD in COPD. ${ }^{21}$ Baroreflex sensitivity (BRS) is a sensitive indicator of cardiac autonomic function and also a measure of cardiovascular risk including morbidity and mortality. ${ }^{22} \mathrm{BRS}$ is defined as the change in interbeat interval (IBI) in milliseconds per unit change in blood pressure. Decrease baroreflex sensitivity is reported as an index of $\mathrm{CV}$ risk and several studies have denoted that BRS is the broadcaster of the CV risk. ${ }^{23-25}$ To the best of our knowledge, there is paucity of literature, revealing the relationship of BRS with disease severity in COPD patients. Hence in the present study, we intended to assess BRS among different stages of COPD (GOLD CRITERIA) and also identify the association of BRS with disease severity.

\section{Materials and Method}

Study Design: This was a cross sectional study conducted in 130 male COPD patients from January 2016 to July 2017. Sample size was estimated conveniently based on logistics, time and budget. We have decided to include 130 male COPD patients attending Department of Pulmonary medicine during the study period will be included in the study. It was designed to assess the pulmonary function tests, baroreflex sensitivity in male COPD patients and also to correlate BRS with FEV1. The study was conducted in Department of Physiology, JIPMER in Collaboration with Department of Pulmonary Medicine, JIPMER. Before the start of the study, approval from JIPMER scientific advisory committee and Institute ethics committee for human studies were obtained. In the study group, Pulmonary function tests (using SpirolabIII) and Baroreflex sensitivity (using FINAPRES) were studied. Later, subjects were classified into four subgroups based on GOLD stage criteria into mild, moderate, severe and very severe COPD.

Selection of Subjects: Male COPD patients (GOLD-Stage I-IV) aged between 35-60 years attending JIPMER pulmonology OPD were included in the study. COPD patients who cannot maintain oxygen saturation above $88 \%$, COPD patients with systemic complications like coronary heart disease, arrhythmia, Stroke and Alcoholics, Diabetic, hypertensive patients, Tobacco chewers were excluded from the study. Subjects were health educated about the disease and are motivated to know their Disease severity \& Cardiovascular risk associated with their Disease.

Experimental Design: The study was carried out in pulmonary function testing laboratory and autonomic function testing laboratory in Department of Physiology, JIPMER between 9 am to $1 \mathrm{pm}$. The laboratory conditions were quiet, the temperature of $25-27 * \mathrm{C}$ and adequate lightening provided. The subjects were explained clearly about study protocol in their native language and written informed consent was obtained from them. The participants were asked to have light Breakfast around $7 \mathrm{am}$ and come for tests around 9 am as the subjects will have difficulty in performing PFT and BRS with the full stomach. The subjects were told to refrain from smoking, drinking caffeinated beverages and the morning dose medications for COPD at least 12 hours before the recording. In case of any adversity in health, such as fever, exacerbation of COPD, poor sleep or physical discomfort, tests were postponed and the subjects were asked to report on another convenient day. Subjects were also asked to stop taking medications affecting their attention like psychotropic drugs (sedatives \& antihistamines).

Statistical Analysis of Data: SPSS version 19 was used for statistical analysis. The data were subjected to 
Kolmogorov-Smirnov normality test. The continuous data such as age, duration of illness, anthropometric parameters (Ht, Wt, WC, HC, WHR, Wht R), heart and blood pressure were expressed as mean with standard deviation and the intergroup differences in mean between mild, moderate, severe and very severe COPD groups were compared using Oneway ANOVA test. BRS was expressed in median with interquartile range and the intergroup differences between mild, moderate, severe and very severe COPD groups were compared using Kruskal- Wallis test. The correlation between BRS and FEV1 was done using Spearman correlation test. The difference was considered statistically significant if probability of chance was less than 0.05 .

\section{Results}

All the anthropometric, PFT \& BRS, parameters were assessed in 130 COPD patients after obtaining informed consent from them and the data were analysed.

\section{Comparison of parameters among different stages of COPD:}

Demographic characteristics: The mean age, duration of illness, anthropometric indices (height, weight, BMI, waist circumference, hip circumference, waist-hip ratio and waist height ratio) of the study group were given in Table 1.

Heart rate and Blood pressure parameters: The mean Heart rate, SBP, DBP, PP, MAP of the study group were given in Table 2.
No significant difference was noted among the four subgroups of COPD.

Blood pressure variability parameters: Comparison of Blood pressure variability parameters among patients in different COPD severity groups was done using Kruskal- Wallis test and the post - hoc (Dunn's) test was performed to find the significant difference among the groups among the BPV parameters, the BRS levels were significantly reduced (Table-3) in very severe, severe and moderate COPD patients when compared to mild COPD patients. Significant negative Correlation $(\mathrm{r}=.322, \mathrm{p}=0.05)$ was found between BRS and FEV1. (Figure 1).

Table 1: Demographic characteristics of study participants $(n=130)$

\begin{tabular}{|l|c|}
\hline Variables & Mean \pm SD \\
\hline Age $($ Years $)$ & $53.37 \pm 5.65$ \\
\hline Duration $($ Years $)$ & $6.92 \pm 2.57$ \\
\hline Height $(\mathrm{cm})$ & $161.33 \pm 7.72$ \\
\hline Weight $(\mathrm{Kg})$ & $55.06 \pm 9.60$ \\
\hline BMI $\left(\mathrm{Kg} / \mathrm{m}^{2}\right)$ & $21.15 \pm 3.47$ \\
\hline Waist $(\mathrm{cm})$ & $89.00 \pm 8.39$ \\
\hline Hip $(\mathrm{cm})$ & $108.77 \pm 16.02$ \\
\hline Waist Hip Ratio & $0.82 \pm 0.09$ \\
\hline Waist Height Ratio & $0.55 \pm 0.04$ \\
\hline
\end{tabular}

The values are expressed in mean with SD

Table: 2 Comparison of Basal heart rate and blood pressure among COPD patients

\begin{tabular}{|l|c|c|c|c|c|c|}
\hline $\begin{array}{l}\text { Cardiovascular } \\
\text { Parameters }\end{array}$ & Total (n=130) & $\begin{array}{c}\text { Mild COPD } \\
(\mathbf{n}=\mathbf{1 8})\end{array}$ & $\begin{array}{c}\text { Moderate } \\
\text { COPD }(\mathbf{n}=\mathbf{4 1})\end{array}$ & $\begin{array}{c}\text { Severe COPD } \\
(\mathbf{n}=\mathbf{4 4})\end{array}$ & $\begin{array}{c}\text { Very Severe } \\
\text { COPD (n= 27) }\end{array}$ & $\begin{array}{c}\text { P value* } \\
\text { HR }\end{array}$ \\
\hline SBP & $120 \pm 13.8$ & $106.25 \pm 4.24$ & $116.53 \pm 4.85$ & $120.97 \pm 5.23$ & $130.58 \pm 6.05$ & 0.001 \\
\hline DBP & $75.9 \pm 13.4$ & $66.76 \pm 3.68$ & $71.25 \pm 5.44$ & $79.05 \pm 6.43$ & $86.08 \pm 4.90$ & 0.004 \\
\hline PP & $43.34 \pm 9.58$ & $39.49 \pm 4.45$ & $45.28 \pm 6.85$ & $41.92 \pm 8.93$ & $44.49 \pm 9.21$ & 0.016 \\
\hline MAP & $90.9 \pm 10.58$ & $79.92 \pm 3.26$ & $86.35 \pm 4.15$ & $93.03 \pm 4.36$ & $100.90 \pm 3.06$ & 0.000 \\
\hline
\end{tabular}

Values are expressed as mean (SD); Comparison of variables between groups done using ANOVA

$*_{p}<0.05$ is statistically significant among the four groups of COPD

HR: heart rate (bpm); SBP: Systolic blood pressure (mmHg); DBP: Diastolic blood pressure (mmHg); PP: pulse pressure (mmHg); MAP: mean arterial pressure $(\mathrm{mmHg})$ 
Table: 3 Comparison of blood pressure variability parameters at rest among COPD patients

\begin{tabular}{|l|l|c|c|c|c|c|}
\hline $\begin{array}{l}\text { HRV } \\
\text { Parameters }\end{array}$ & \multicolumn{1}{|c|}{ Total $(\mathbf{n = 1 3 0 )}$} & $\begin{array}{c}\text { Mild COPD } \\
(\mathbf{n}=\mathbf{1 8})\end{array}$ & $\begin{array}{c}\text { Moderate } \\
\text { COPD }(\mathbf{n}=\mathbf{4 1})\end{array}$ & $\begin{array}{c}\text { Severe COPD } \\
(\mathbf{n}=\mathbf{4 4})\end{array}$ & $\begin{array}{c}\text { Very severe } \\
\text { COPD }(\mathbf{n}=\mathbf{2 7})\end{array}$ & \begin{tabular}{c} 
P value* \\
\hline Blood Pressure Variability Parameters
\end{tabular} \\
\hline BRS & $5.41(2.88)$ & $9.64(4.97)$ & $6.21(2.16)$ & $5.07(2.45)$ & $4.02(2.21)$ & 0.002 \\
\hline
\end{tabular}

Values are expressed as Median (Interquartile range); Comparison of variables between groups done using Kruskal Wallis test ${ }^{*} \mathrm{p}<0.05$ is statistically significant among the four groups of COPD

BRS- Baroreflex sensitivity $(\mathrm{ms} / \mathrm{mmHg}$ )

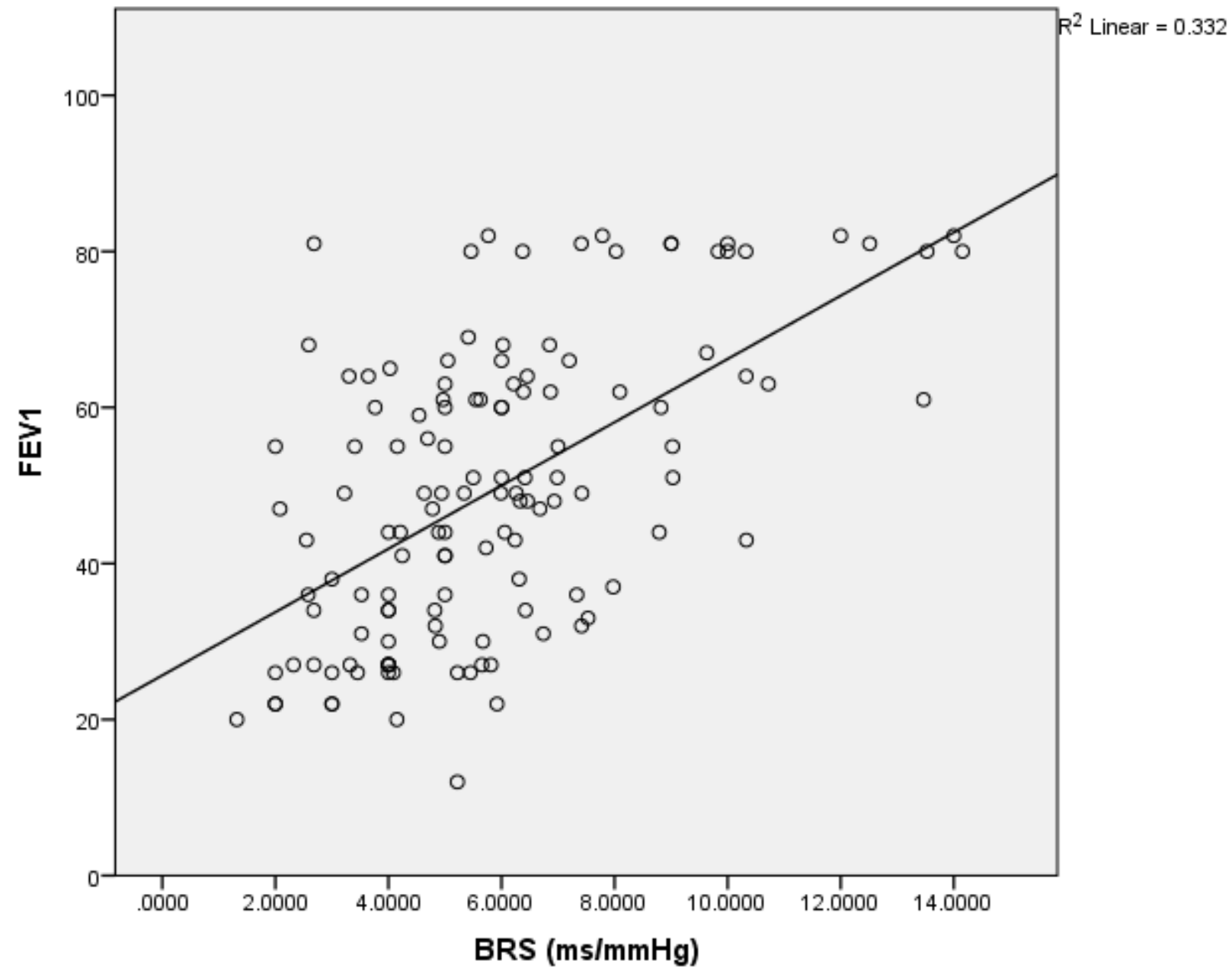

Figure 1: Linear relationship between $\mathrm{FEV}_{1}$ and BRS.

\section{Discussion}

In our study population of 130 male COPD patients, anthropometric parameters such as height, weight, BMI, waist circumference, hip circumference, waisthip ratio and waist height ratio were assessed. Later the mean height, weight, BMI (20.1, 20.8, 21 and 22,), waist circumference, hip circumference, waist-hip ratio $(0.81,0.82,0.83$ and 0.85$)$ and waist height ratio $(0.55,0.54,0.55$ and 0.55$)$ were compared among the four subgroups of COPD patients. We found that none of the anthropometric parameters showed statistical significance among the four subgroups of COPD patients. Baroreceptors sense the fluctuation in the blood pressure based on the stretch produced on the vessel wall. Baroreflex mechanism would increase parasympathetic activity and decrease sympathetic activity in response to an increase in blood pressure. ${ }^{28}$ In our study, we measured Baroreflex sensitivity in COPD patients using FINAPRES. 
In our study, we found decreased levels of BRS (5.41) in COPD patients when compared with the previous studies. ${ }^{29}$ Decreased BRS is an indicator of reduced sympathovagal imbalance. ${ }^{28}$ Our findings were similar to the study done by D Patakas et al., which showed that in COPD patients, the responsiveness of the baroreflex mechanism is reduced in response to rising in blood pressure. ${ }^{26}$ However in that study, BRS was assessed by change in heart rate and blood pressure induced by injecting phenylephrine. When we compared BRS levels among four subgroups of COPD patients, we found that BRS levels were significantly reduced $(p<0.05)$ in very severe, severe and moderate COPD patients when compared to mild COPD patients. We also correlated BRS with disease severity and found that Baroreflex sensitivity showed a negative correlation with disease severity. There was linear relationship existed between BRS and FEV1 (Figure-1). These results were in accordance with the study done by Christian F. Clarenbach et.al. ${ }^{27}$ Impaired baroreflex sensitivity increases sympathetic activity, thereby increases $\mathrm{CV}$ risk. Studies done by La Rovere MT et al., Robinson TG et al., Johansson $\mathrm{M}$ et al., showed that BRS is also the broadcaster of the $\mathrm{CV}$ risk. ${ }^{23-25}$ Increased sympathetic activity was again confirmed with significant increase $(\mathrm{p}<0.05)$ in rest DBP and HR as the disease severity is increased. So, COPD patients with reduced BRS have reduced sympathovagal regulation and are prone to $\mathrm{CV}$ risk. The risk increases as the severity of the disease is increased.

\section{Conclusion}

From the present study, we conclude that in COPD patients, as the disease severity increases, the levels of BRS were decreased. BRS is associated with COPD disease severity.

\section{Conflict of Interest: Nil}

Source of Funding: JIPMER intramural grant

Ethical Clearance: Institute ethics committee for human studies, JIPMER

\section{References}

1. Reilly JJ, Silverman EK, Shapiro SD. In: Harrison's Principles of Internal Medicine. Chronic obstructive pulmonary disease. $19^{\text {th }}$ Edn. 2012;312: 1700.

2. World Health Organization. Burden of COPD. http://. www.who.int/respiratory/copd/burden
3. Jindal SK, Aggarwal AN, Gupta D, Agarwal $\mathrm{R}$, Kumar R, Kaur $\mathrm{T}$, et al. Indian study on epidemiology of asthma, respiratory symptoms and chronicbronchitis in adults (INSEARCH). Int J Tuberc Lung Dis 2012;16:1270-7.

4. Jindal SK, Aggarwal AN, Gupta D. A review of the population studies from India to estimate national burden of chronic obstructive pulmonary disease and its association with smoking. Indian $\mathrm{J}$ Chest Dis Allied Sci2001;43:139-47.

5. Engström G, Joseph F, Cha E, Scharf SM. Chronic obstructive pulmonary disease as an independent risk factor for cardiovascular morbidity. International Journal of COPD. 2009; 4:337-49

6. Salvi S, Agarwal A. India needs a national COPD prevention and Control program. J Assoc Physicians India 2012; 60 Suppl: 5-7.

7. Agustí AG, Noguera A, Sauleda J, Sala E, Pons J, Busquets X. Systemic effects of chronic obstructive pulmonary disease. Eur Respir J. 2003; 21:347360.

8. Hansell AL, Walk JA, Soriano JB. What do chronic obstructive pulmonary disease patients die from? A multiple cause coding analysis. Eur Respir J 2003;22:809-814.

9. Jousilahti P, Vartiainen E, Tuomilehto J, Puska P. Symptoms of chronic bronchitis and the risk of coronary disease. Lancet 1996;348:567-572.

10. Engstrom G, Wollmer P, Hedblad B, Juul-Mo“ ller S, Valind S, Janzon L. Occurrence and prognostic significance of ventricular arrhythmia is related to pulmonary function: a study from "men born in 1914", Malmo", Sweden. Circulation 2001;103:3086-3091.

11. Anthonisen NR, Connett JE, Enright PL, Manfreda J; Lung Health Study Research Group. Hospitalizations and mortality in the Lung Health Study. Am J Respir Crit Care Med. 2002;166: 333339.

12. Sin DD, Man SFP. Chronic obstructive pulmonary disease: A novel risk factor for cardiovascular disease. Can J Physiol Pharmacol. 2005;83:8-13.

13. Joseph Finkelstein, Eunme Cha, Steven M Scharf Chronic obstructive pulmonary disease as an independent risk factor for cardiovascular morbidity. International journal of COPD, 2009 September 3.

14. Hedblad B, Janzon L, Valind S. Respiratory decline 
in smokers and ex-smokers - an independent risk factor for cardiovascular disease and death. J Cardiovasc Risk. 2000;7 267-72

15. Sin DD, Wu L, Man SF. The relationship between reduced lung function and cardiovascular mortality: a population-based study and a systematic review of the literature. Chest.2005; 127:1952-59.

16. Sin DD, Man SF. Why are patients with chronic obstructive pulmonary disease at increased risk of cardiovascular diseases? The potential role of systemic inflammation in chronic obstructive pulmonary disease. Circulation 2003; 107:15141519

17. Anthonisen NR, Connett JE, Kiley JP, et al. Effects of smoking intervention and the use of an inhaled anticholinergic bronchodilator on the rate of decline of FEV1: the Lung Health Study. JAMA 1994; 272:1497-1505

18. Multiple Risk Factor Intervention Trial Research Group. Multiple Risk Factor Intervention Trial: risk factor changes and mortality results. JAMA 1982; 248:1465-1477

19. Stein PK, Nelson P, Rottman JN, Howard D, Ward $\mathrm{SM}$, Kleiger RE, et al. Heart rate variability reflects severity of COPD in PiZ $\alpha 1$-antitrypsin deficiency. Chest 1998;113: 327-33.

20. Stewart AG, Waterhouse JC, Howard P. Cardiovascular autonomic nerve function in patients with hypoxaemic chronic obstructive pulmonary disease. Eur Respir J 1991;4: 1207-14.

21. Engstrom G, Gerhardsson de Verdier M, Dahlback M, Janson C, Lars Lind L. BP variability and cardiovascular autonomic function in relation to forced expiratory volume: a population-based study. Chest 2009;136: 177-83.
22. Swenne CA. Baroreflex sensitivity: mechanisms and measurement. Neth Heart J 2013;21:58-60.

23. La Rovere MT, Bigger JT, Marcus Fl, Mortara A, Schwartz PJ. Baroreflex sensitivity and heart rate variability in identification of total cardiac mortality after myocardial infarction. Lancet 1998; 351: 478484.

24. Johansson M, Gao SA, Friberg P, Annerstedt $\mathrm{M}$, Carlstrom $\mathrm{J}$, Ivarsson $\mathrm{T}$, et al. Baroreflex effectiveness index and baroreflex sensitivity predicts all- cause mortality and sudden death in hypertensive patients with chronic renal failure. $\mathrm{J}$ Hypertens 2007; 25:163-168.

25. Robinson TG, Dawson SL, Eames PJ, Panerai RB, Potter JF. Cardiac baroreceptor sensitivity predicts long term outcome after acute ischemic stroke. Stroke 2003; 34: 705-712.

26. .Patakas D, Louridas G, Kakavelas E. Reduced baroreceptor sensitivity in patients with chronic obstructive pulmonary disease. Thorax 1982; 37:292-5.

27. Christian F. Clarenbach, Oliver Senn, Noriane A. et.al, Determinants of endothelial function in patients with COPD. Eur Respir J 2013; 42: 1194 1204

28. La Rovere MT, Pinna GD, Raczak G. Baroreflex sensitivity: measurement and clinical implications. Ann Noninvasive Electrocardiol Off J Int Soc Holter Noninvasive Electrocardiol Inc. 2008 Apr;13(2):191-207.

29. Mathias CJ, Bannister R. Investigation of autonomic disorders. In: Mathias CJ, Bannister R (eds). Autonomic failure: a textbook of clinical disorders of the autonomic nervous system. 4th ed. Great Britain: Oxford University Press;1999. 196$210 \mathrm{p}$. 